\title{
Fabrication of Copper Nano-Filter Membrane and its use in the Purification of Contaminated Water
}

\author{
Abdulwahab K. O. ${ }^{1 *}$, Otusote C. M. ${ }^{2}$ and Adams L. A. ${ }^{3}$ \\ ${ }^{1,2,3}$ Department of Chemistry, Faculty of Science, University of Lagos, Akoka, Lagos State, Nigeria \\ Corresponding Author: *kabdulwahab@unilag.edu.ng
}

https://doi.org/10.36263/nijest.2020.01.0177

\begin{abstract}
Copper nanoparticles were synthesised by the green method using African spinach and peppermint leaves extract as both reducing and capping agents. The synthesized nanoparticles were then characterized by Energy Dispersive Spectroscopy, (EDS), Scanning Electron Microscopy (SEM) and Fourier Transform Infra-Red Spectroscopy (FTIR). EDS confirmed the formation of copper nanoparticles and SEM images showed spherical nanoparticles with an average size of $3.44 \mu \mathrm{m}$. FTIR showed that the functional groups on the leaves' extracts were capped on the surface of the nanoparticles. The nanoparticles were then casted into a nano-filter membrane using cellulose actetate and used to filter contaminated water gotten from a canal at the University of Lagos. The filtration efficiency of this nano-filter was compared with the ordinary cellulose acetate membrane and the result showed that the copper nano-filter membrane gave an odourless, cleaner water than that of ordinary cellulose acetate membrane. The microbial analysis also revealed that about 96.5 $\%$ of the bacteria was removed using the copper nano-filter membrane.
\end{abstract}

Keywords: Green synthesis, Copper nanoparticles, Waste water purification, Nano-filter membrane, Antimicrobial

\subsection{Introduction}

Globally, there is a general problem of water pollution. Most of our water bodies are polluted and are not fit for usage. As a result, a lot of water treatment methods have been developed. However, most of these methods are very expensive, not easily available and some of them are not as efficient. Therefore, there is need to provide easy, cost friendly and environmental benign method of treating our water. This can be achieved with the use of copper nanoparticles.

Copper nano particles possess unique characteristics which include catalytic (Judai et al., 2011), high electrical conductivity (Din and Rehan 2017), magnetic (Ghasemi et al., 2011) optical (Wu et al., 2010) and antibacterial/antifungal activities (Ramyadevi et al., 2012, Zain et al., 2014). The antimicrobial activity has led to numerous applications such as in cosmetics, food processing (Pal, 2017) drug delivery (Varshney et al., 2012, Kailasa et al., 2018) sensors (Ghotto et al., 2019) and in water treatment (Chen et al., 2014). In comparison with precious metals, such as gold, silver, or platinum, copper has the advantage of being in high abundance and it is cheap. The property of copper nanoparticles mainly depends on the synthesis route and their reaction parameters. Various synthetic routes have been employed for the synthesis of copper nanoparticles including chemical reduction (Dong et al., 2018, Gajera, 2014), electrochemical (Fernandez et al., 2017), hydrothermal (Seku et al., 2018), microwave assisted techniques (Galletti et al., 2013) and biological synthesis (Kulkarni and Kulkarni, 2013).

These days, the emphasis has been shifted towards the green synthesis of Cu-NPs by using plant extracts as stabilizers and reducing agents (Subbaiya and Selvam, 2015). This will eliminate the use of toxic chemicals and so promote environmental friendliness. In this research, copper nanoparticles were prepared using the green synthesis method. The copper nanoparticles were synthesized from copper sulphate solution with African spinach and peppermint leaves extract as capping/reducing agents under nitrogen to prevent oxidation of the copper nanoparticles. The synthesized nanoparticles 
were then characterized by Energy Dispersive Spectroscopy (EDS), Scanning Electron Microscopy (SEM) and Fourier Transform Infra-Red Spectroscopy (FTIR). The synthesized copper nanoparticles were made into a nano-filter membrane filter using cellulose acetate as support. The nano copper filter membrane was then tested by using it to filter water collected from a canal in the University of Lagos. The efficiency of this nano-filter membrane was compared with the ordinary cellulose acetate membrane by studying the extent to which they can successfully treat colour, odour and micro organisms.

\subsection{Methodology}

\subsection{Preparation of spinach and peppermint leaves extract}

Fresh African Spinach and peppermint leaves were bought from a local market in Lagos. The leaves were washed several times with distilled water and were air dried for a few days. Then the leaves were ground to a fine powder and kept separately in different air-tight containers. $5 \mathrm{~g}$ of spinach or peppermint powder was weighed and transferred to a beaker. $50 \mathrm{ml}$ of distilled water was measured and transferred to the beaker. It was placed on a hot plate and allowed to boil for 15 minutes. After boiling, it was allowed to cool and filtered using a filter paper. The filtrate was kept in a bottle and kept refrigerated until needed (Abdulwahab et al., 2019).

\subsection{Preparation of precursor solutions}

Copper sulphate pentahydrate salt was weighed $(0.50 \mathrm{~g}, 0.04 \mathrm{M})$ and dissolved in $10 \mathrm{ml}$ distilled water in a beaker. The resulting mixture was transferred into a $50 \mathrm{ml}$ standard flask and distilled water was added up to the mark. $5 \mathrm{~g}$ of ascorbic acid was dissolved in $50 \mathrm{ml}$ dissolved water. It was stirred until a clear solution was obtained.

\subsection{Green synthesis of copper nanoparticles with peppermint and spinach extracts}

$50 \mathrm{ml}$ of the copper sulphate pentahydrate solution was measured into a three-necked round bottom flask. Then $50 \mathrm{ml}$ ascorbic acid was added to the copper sulphate solution followed by $25 \mathrm{ml}$ of the extracts (peppermint and spinach). The resulting mixture was heated on a hot plate for 1 hour with rapid stirring at $80^{\circ} \mathrm{C}$ using a magnetic stirrer under nitrogen atmosphere (Abdulwahab et al., 2019).

On the addition of ascorbic acid, the colour changes from blue to light green. The green solution now turned reddish brown after adding the extracts indicating the formation of copper nanoparticles. The brown solution was then centrifuged, washed with distilled water and left to dry completely.

\subsection{Casting of cellulose acetate membrane}

The casting of cellulose acetate membrane was carried out following procedure in literature but with modifications (Kaiser et al., 2017). $5 \mathrm{~g}$ of cellulose acetate was weighed into a conical flask and $75 \mathrm{ml}$ of acetone was added and stirred using a magnetic stirrer for 1 hour. After 1 hour, $3 \mathrm{~g}(0.05$ mole $)$ of sodium chloride and $3 \mathrm{ml}$ of glycerol were added to the mixture and was left to stir for 30 minutes. The resulting polymer was casted onto the glass plate and left to dry. The dried glass plate containing the membrane was put into a tray of distilled water for 10 minutes to etch out the sodium chloride so that pores can form on the membrane to enable filtering.

\subsection{Casting of copper nano-filter membrane}

$0.1 \mathrm{~g}$ of copper nanoparticles was dissolved in $3 \mathrm{ml}$ of dimethyl sulphoxide and then added to the already made polymer solution and was stirred for 30 minutes. The functionalized polymer mixture was the casted onto a glass plate and left to dry. The copper nano-filter membrane was then put in a tray of distilled water for 10 minutes to etch out the sodium chloride and create pores in the nanofilter cellulose acetate membrane to enable it filter.

The ordinary cellulose membrane and the copper nano-filter membrane were then used to filter contaminated water from a canal by passing a $100 \mathrm{ml}$ of the water each through the ordinary membrane and the copper nano-filter membrane. 


\subsection{Microbiological analysis of water}

The microbial activity was determined using the pouring plate counting method. The media used for the bacteriological analysis of water include plate count agar (PCA), nutrient agar (NA), potato dextrose agar (PDA) and eosin methylene blue agar (EMB). All the media used were weighed out and prepared according to the manufacture's specification, with respect to the given instructions and directions. The microbes present in the sample were determined by plating out $0.1 \mathrm{ml}$ of $10^{-1}$ dilution series of water sample on the nutrient agars. Duplicates were made and incubated aerobically at $37^{\circ} \mathrm{C}$ for 24 hours (nutrient agar plates) while the potato agar plates were incubated at room temperature for 3 - 5 days. The thermo-tolerant bacteria were incubated at $44{ }^{\circ} \mathrm{C}$ (Bartram and Pedley 1996). The pure cultures of the isolates were subjected to various morphological and biochemical characterization tests to determine the identity of the isolates with reference to Bergey's Manual of Determinative Bacteriology (Buchanan and Gibbons, 1974).

\subsection{Results and Discussion}

\subsection{Characterization of copper nanoparticles}

After copper nanoparticles have been successfully synthesized from African spinach and peppermint leaf extracts, the brown coloured powder obtained was characterized by Fourier transform infrared spectroscopy (FTIR), scanning electron microscope (SEM) and energy dispersive spectroscopy (EDS). The EDS and FTIR results are similar to what was obtained in an earlier study by the authors (Abdulwahab et al., 2019) on copper nanoparticles using the same procedure.

\subsection{Fourier Transform Infrared Spectroscopy}

The peak at $3321 \mathrm{~cm}^{-1}$ is attributed to $\mathrm{OH}$ stretching. This peak became broadened and there is a shift in the IR spectrum of nanoparticles capped with extract indicating that there is adsorption of $\mathrm{OH}$ bond on the surface of the nanoparticles (Figure 1). The $\mathrm{C}=\mathrm{O}$ stretching peak (1637) found in the extract disappeared in the synthesized nanoparticles capped with extract suggesting that oxidation must have taken place, hence confirming the use of the extracts as reducing agent.

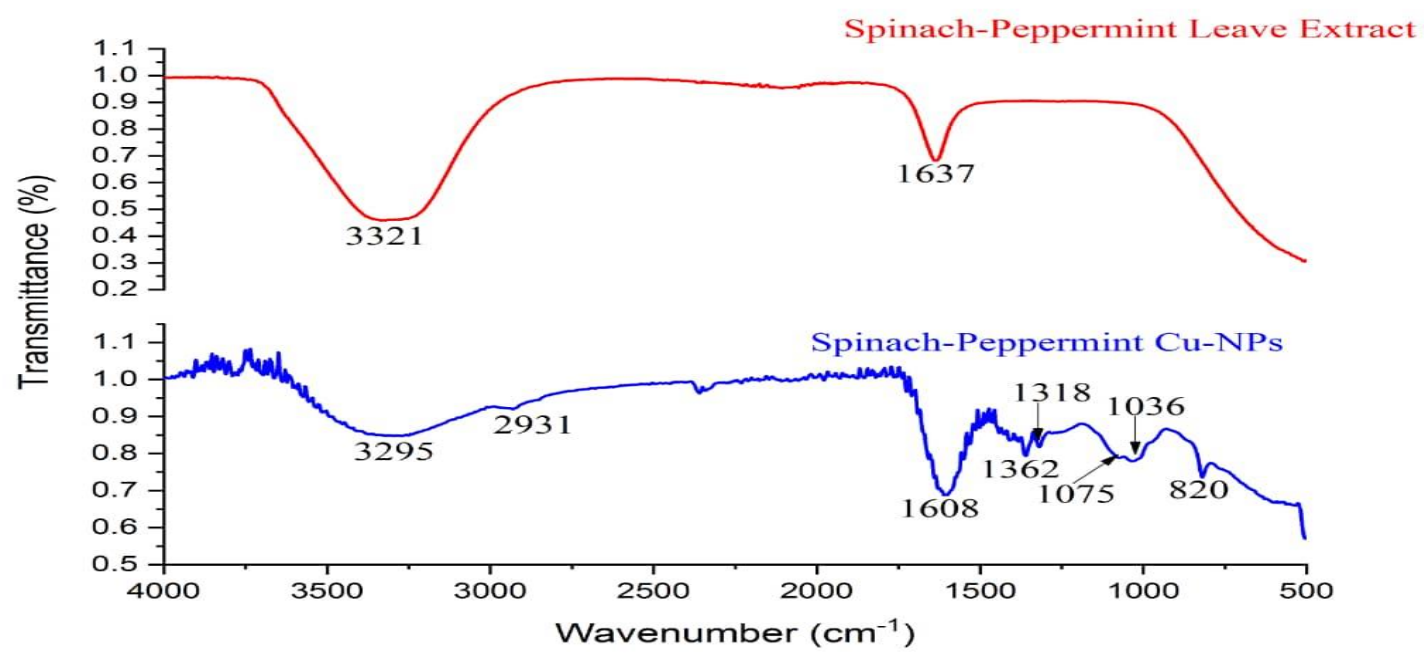

Figure 1: FTIR spectra of spinach-peppermint leave extracts (top) and spinach-peppermint capped $\mathrm{Cu}-\mathrm{NPs}$ (bottom)

\subsection{Energy dispersive spectroscopy (EDS)}

The EDS result of the copper nanoparticles for the peppermint and spinach leaves was done. The result showed 55\% of copper (Figure 2). The presence of oxygen showed it has undergone some form of oxidation. The carbon can be attributed to the organic compounds present in the peppermint and spinach leaf extracts which is confirmed by the FTIR result in Figure 1. In comparison with similar method reported earlier by Aher et al. (2019), they got $39.16 \%$ of copper. This shows that the leaf extracts used in this study were better at reducing the copper ions and stabilizing them. 


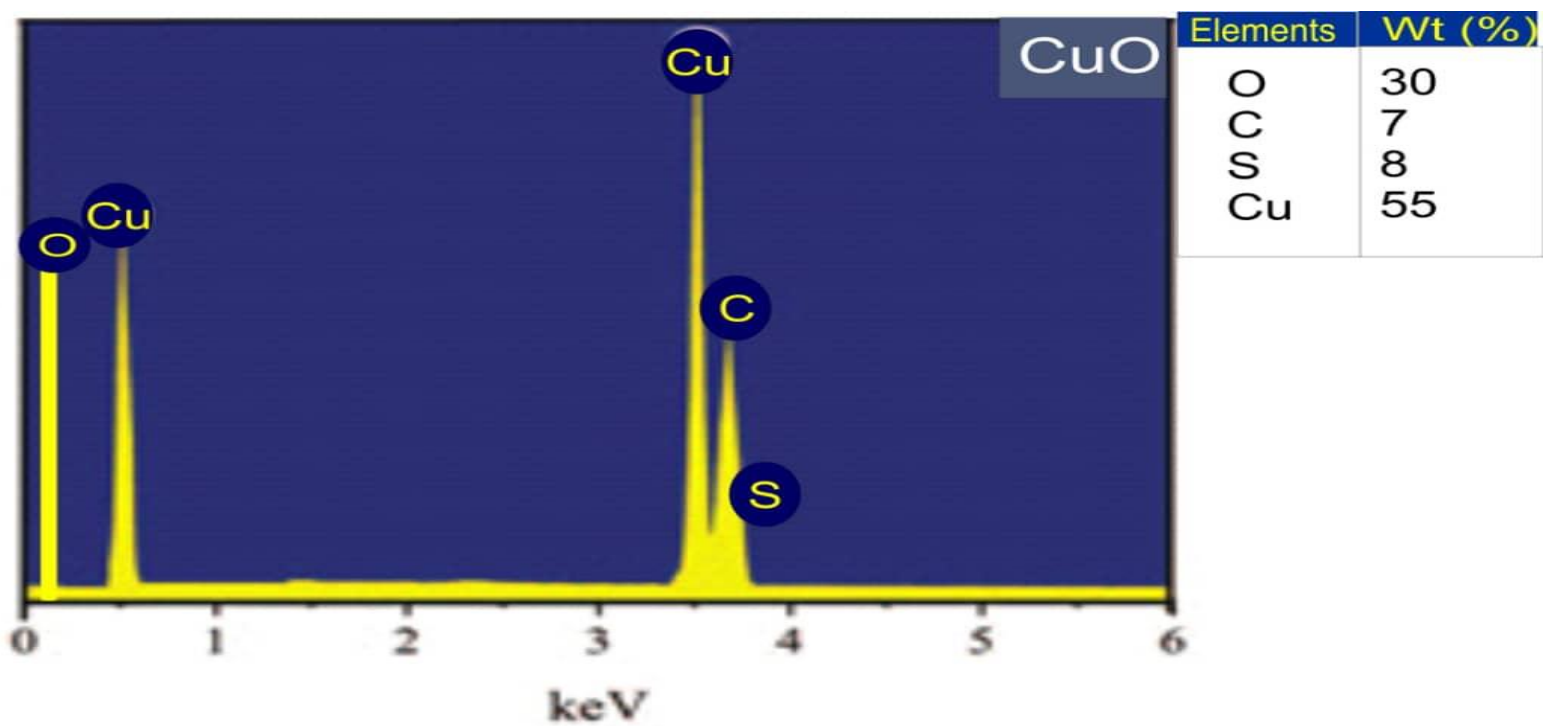

Figure 2: EDX spectrum of copper nanoparticles capped with spinach and peppermint leaves extracts

\subsection{Scanning electron microscopy (SEM)}

The SEM images are shown in Figure 3. The copper nanoparticles are spherical in shape and are evenly distributed with an average size of about $3.44 \mu \mathrm{m}$.
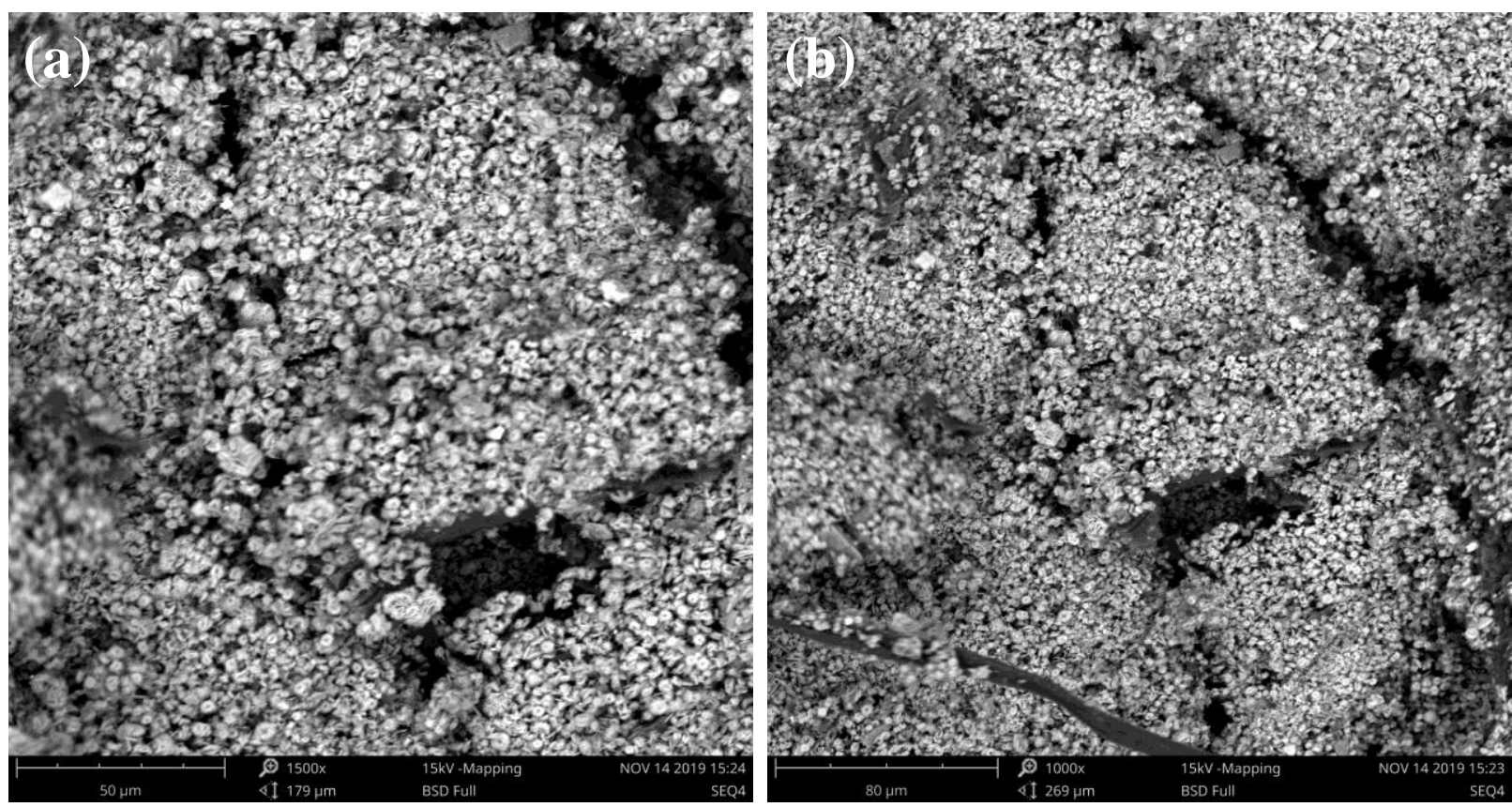

Figure 3: SEM images of copper nanoparticles at different magnifications (a) at $50 \mu \mathrm{m}$ and (b) $80 \mu \mathrm{m}$

3.5 Comparison of the efficiency of ordinary cellulose acetate membrane with nano-filter membrane in the treatment of dirty canal water

Contaminated water was collected from a canal on campus and purified to study the efficiency of nano-filter membrane in the removal of colour, odour and micro-organisms. The filtrate collected using copper nano-filter membrane was clean, odourless and colourless while the filtrate collected using ordinary cellulose acetate membrane still had odour and was not as clean as that obtained from the nano -filter (Figure 4). 

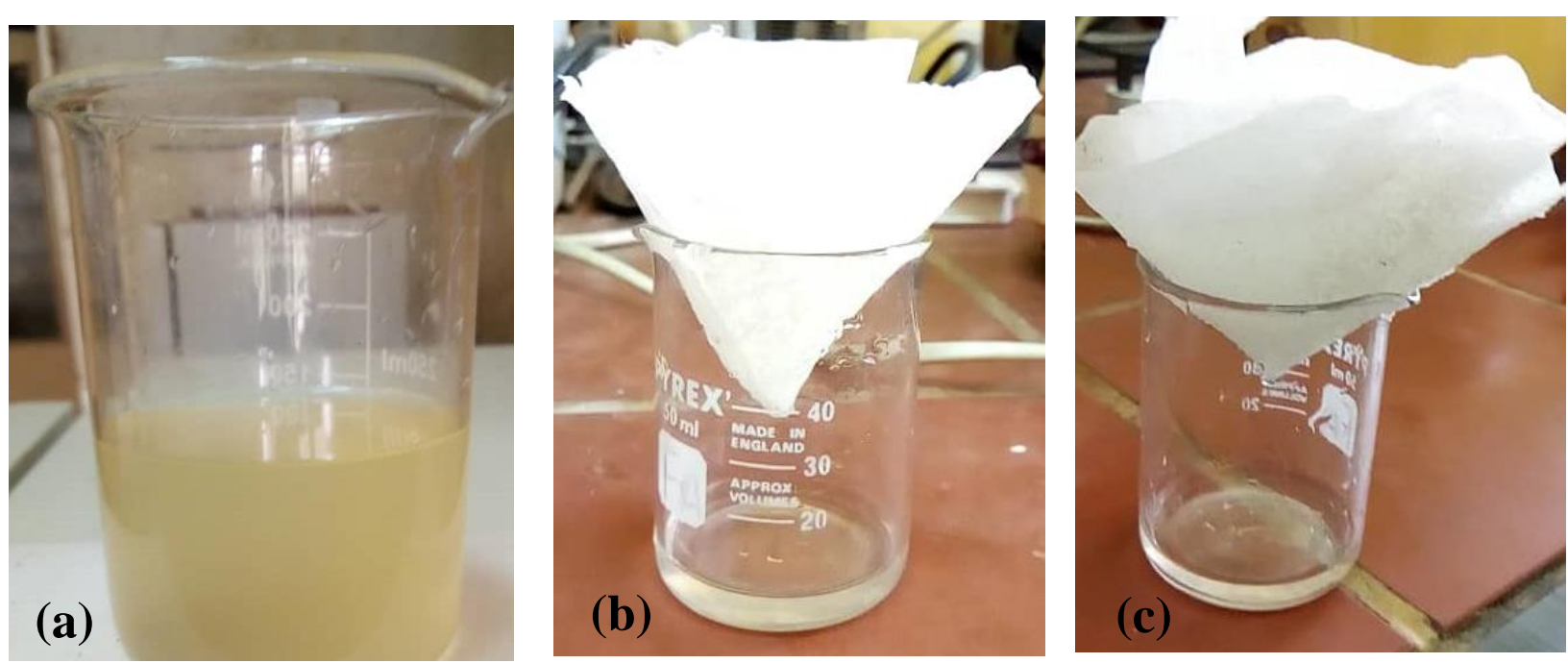

Figure 4: (a) water sample before purification (b) filtrate obtained using ordinary cellulose membrane (c) filtrate obtained using nano-copper filter membrane

Table 1: Microbial analysis obtained for the water before and after treatment

\begin{tabular}{lllll}
\hline Sample & $\begin{array}{l}\text { Total Heterotrophic } \\
\text { Bacteria }(\mathrm{cfu} / \mathrm{ml})\end{array}$ & $\begin{array}{l}\text { Total Heterotrophic } \\
\text { Fungi }(\mathrm{cfu} / \mathrm{ml})\end{array}$ & $\begin{array}{l}\text { Total Faecal } \\
\text { Coliforms }(\mathrm{cfu} / \mathrm{ml})\end{array}$ & Predominant Species \\
\hline $\begin{array}{l}\text { Canal water } \\
\text { (before filtration) }\end{array}$ & $2.30 \times 10^{5}$ & $3.0 \times 10^{4}$ & $1.10 \times 10^{3}$ & $\begin{array}{l}\text { Aspergillus niger } \\
\text { Fusarium spp } \\
\text { Pseudomonas aerugious, } \\
\text { Staphylococcus aureus } \\
\text { Escherichia coli } \\
\text { Bacillus sps }\end{array}$ \\
Bacillus spp
\end{tabular}

The microbial analysis done on the water before and after treatment revealed that the contaminated water was heavily contaminated with lots of disease-causing bacteria such as Escherichia coli (an indicating organism) that shows the water sample is heavenly polluted with faecal contaminants. Also isolated in the contaminated water are Pseudomonas aerugious, Staphylococcus aureus and Aspergillus niger (Fungus) which secretes Alflotoxin that affects the nerves of humans. In the treated water only Bacillus sps was isolated. All the fungi and faecal contaminants have been removed in the process of treatment.

The contaminated water was found to have a total count of $230,000 \mathrm{cfu} / \mathrm{ml}$ for heterotrophic bacteria; while in the treated water a total count of $8000 \mathrm{cfu} / \mathrm{ml}$ was obtained from water treated with copper nano-filter membrane and $11,000 \mathrm{cfu} / \mathrm{ml}$ was obtained from water treated with ordinary cellulose membrane. These results show that the nano-filter membrane not only succeeded in removing poisonous bacteria but also has removed $96.5 \%$ of the heterotrophic bacteria found. The killing of $96.5 \%$ microbes within a short contact time (less than 10 minutes) shows that the nanofilter membrane is very efficient as compared to method reported in literature that requires a longer contact time for this to be achievable (Jia et al., 2012). This indeed revealed the potency of copper nanoparticles as anti-microbial and antifungal substance as sighted in literatures (Yoon et al., 2007, Camacho-Flores et al., 2015). Research has shown that one of the mechanisms by which copper carries out its antimicrobial property involves the release of copper ions into the water resulting in rapid membrane damage and DNA degradation of the microbes when they come in contact with the copper surface (Ren et al., 2009, Santo et al., 2012, Zain et al., 2014). 


\subsection{Conclusions}

Copper nanoparticles were successfully synthesized from copper sulphate salt by the green method using peppermint and African spinach leaves extracts as natural reducing and capping agents. The copper nanoparticles were characterized using SEM, FTIR and EDS.

The synthesized copper nanoparticles were casted into a nano-membrane and then tested as filter for waste water. Its efficiency was tested for waste water filtration by comparing with ordinary cellulose acetate membrane and was found to give cleaner and odourless water than that obtained from ordinary cellulose acetate membrane. The microbial analysis also revealed that the poisonous micro-organisms were removed during filtration showing the anti-microbial potency of copper nanoparticles. This nano-filter is very efficient in removing about $96.5 \%$ of the microbes.

\section{References}

Abdulwahab, K.O., Ogunyinka, T., Kolade, S.O. and Adams, L.A. (2019). Green Synthesis of Copper Nanoparticles, Characterization and their Catalytic Application in the Synthesis of Dibenzoxazepine. Records of Chemical Sciences, Federal University of Dutsin-Ma, Katsina State, 1, pp. 45-49.

Aher, A.R., Han, S.H., Vikhe, A.S. and Kuchekar, S.R. (2019). Green Synthesis of Copper Nanoparticles Using Syzygium Cumin, Leaf Extract, Characterization and Antimicrobial Activity. Chemical Science Transactions, 8, pp. 1-6.

Bartram, J. and PedleyWater, S. (1996). Quality Monitoring - A Practical Guide to the Design and Implementation of Freshwater Quality Studies and Monitoring Programmes. Edited by Jamie Bartram and Richard Balance, Published on behalf of United Nations Environment Programme and the World Health Organization (C) 1996 UNEP/WHO ISBN 0419223207.

Buchanan, R.E. and Gibbons, N.E. (1974). Bergey's Manual of Determinative Bacteriology. $8^{\text {th }}$ Edition. The Williams and Wilkins company, Baltimore.

Chen, H., Zheng, X., Chen, Y., Li, M., Liu, K. and Li, X. (2014). Influence of Copper Nanoparticles on the Physical-Chemical Properties of Activated Sludge. Plos one, 9, e92871, pp. 1-8.

Din, M.I and Rehan, R. (2017). Synthesis, Characterization, and Applications of Copper Nanoparticles. Analytical Letters, 50, pp. 50-62.

Dong, Y., Wang, K., Tan, Y., Wang, Q., Li , J., Mark, H. and Zhang, S. (2018). Synthesis and characterization of pure copper nanoparticles using wood inherent architecture as a natural template. Nanoscale Research Letter, 13, pp. 119-126.

Fernandez, B.P., Yerga, D.M. and Garcia, A.C. (2017). Galvanostatic electrodeposition of copper nanoparticles on screen-printed carbon electrodes and their application for reducing sugars determination. Talanta, 175, pp. 108-113.

Camacho-Flores, B.A., Martínez-Álvarez, O., Arenas-Arrocena, M.C., Garcia-Contreras, R., ArguetaFigueroa L., de la Fuente-Hernández, J. et al. (2015). Copper: Synthesis Techniques in Nanoscale and Powerful Application as an Antimicrobial Agent. Journal of Nanomaterials, pp. 1-10.

Gajera, U. K. A. D. H. P. (2014). Synthesis of copper nanoparticles by two different methods and size comparison. International Journal of Pharmaceutical and Bio Sciences, 5, pp. 533-540.

Galletti, A. M. R., Antonetti, C., Marracci, M., Piccinelli, F. and Tellini, B. (2013). Novel microwave synthesis of $\mathrm{Cu}$ nanoparticles in the absence of any stabilizing agent and their antibacterial and antistatic applications. Applied Surface Science, 280, pp. 610-618. 
Ghasemi, A., Ghasemi, E. and Paimozd, E. (2011). Influence of copper cations on the magnetic properties of NiCuZn ferrite nanoparticles. Journal of Magnetism and Magnetic Materials, 323, pp. $1541-1545$.

Ghotto, S.A., Khuhawar, M.Y., Jahangir, T.M. and Din-Mangi, J. (2019). Applications of copper nanoparticles for colorimetric detection of dithiocarbamate pesticides. Journal of Nanostructure in Chemistry, 9, pp. 77-93.

Jia, B., Mei, Y., Cheng, L., Zhou, J. and Zhang, L. (2012). Preparation of copper nanoparticles coated cellulose films with antibacterial properties through one-step reduction. Applied Materials and Interfaces, 4, pp. 2897-2902.

Judai, K., Numao, S., Nishijo, J. and Nishi, N. (2011). Insitu preparation and catalytic activation of copper nanaoparticles from acetylide molecules. Journal of Molecular Catalysis A: Chemical, 347, pp. 28-33.

Kailasa, S.K., Koduru, J.R., Desai, M.L., Park, T.J., Singhal, R.K. and Basu, H., (2018). Recent progress on surface chemistry of plasmonic metal nanoparticles for colorimetric assay of drugs in pharmaceutical and biological samples. Trends in Analytical Chemistry, 105, pp. 106-120.

Kaiser, A., Stark,W.J. and Grass, R.N. (2017). Rapid Production of a Porous Cellulose Acetate Membrane for Water Filtration using Readily Available Chemicals. Journal of Chemical Education, 94, pp. 483-487.

Kulkarni, V. D. and. Kulkarni, P. S. (2013). Green synthesis of copper nanoparticles using Ocimum Sanctum leaf extract. International Journal Chemical Studies, 1, pp. 1-4.

Pal, M. (2017). Nanotechnology: A New Approach in Food Packaging. Journal of Food Microbiology Safety Hygiene, 2, doi:10.4172/2476-2059.1000121

Ramyadevi, J., Jeyasubramanian, K., Marikani, A., Rajakumar, G. and Rahuman, A.A. (2012). Synthesis and antimicrobial activity of copper nanoparticles, Materials Letters, 71, pp. 114-116.

Ren, G., Hu, D., Cheng, E.W.C., Vargas-Reus, M.A., Reip, P. and Allaker, R.P. (2009). Characterisation of copper oxide nanoparticles for antimicrobial applications. International Journal of Antimicrobial Agents, 33, pp. 587-590.

Seku, K., Ganapuram,B.R., Pejja, B., Kotu, G.M. and Narasimha, G. (2018). Hydrothermal synthesis of copper nanoparticles, characterisation and their biological applications. International Journal of Nano Dimensions, 9, pp. 7-14.

Santo, C.E., Quaranta, D. and Grass, G. (2012). Antimicrobial metallic copper surfaces kill Staphylococcus haemolyticus via membrane damage. Microbiology Open, 1, pp. 46-52.

Subbaiya, R. and Masilamani- Selvam. M. (2015). Green Synthesis of Copper Nanoparticles from Hibicus Rosasinensis and their antimicrobial, antioxidant activities. Research Journal of Pharmaceutical, Biological and Chemical Sciences, 6, pp. 1183-1190.

Varshney, R., Bhadauria, S. and Gaur, M.S. (2012). A review: Biological synthesis of silver and copper nanoparticles. Nano Biomedicine and Engineering, 4, pp. 99-106.

Wu, W., Aiello, M., Zhou, T., Berliner, A., Banerjee, P. and Zhou, S. (2010). In-situ immobilization of quantum dots in polysaccharide-based nanogels for integration of optical $\mathrm{pH}$-sensing, tumor cell imaging, and drug delivery. Biomaterials, 31, pp. 23-31.

Yoon, K.Y., Hoon- Byeon, J., Park, J.H. and Hwang, J. (2007). Susceptibility constants of Escherichia coli and Bacillus subtilis to silver and copper nanoparticles. Science of the Total Environment, 373, pp. $572-575$. 
Zain, N. M., Stapley, A.G. and Shama, G., (2014). Green synthesis of silver and copper nanoparticles using ascorbic acid and chitosan for antimicrobial applications. Carbohydrate Polymers, 112, pp. 195- 202.

Cite this article as:

Abdulwahab K. O., Otusote C. M. and Adams L. A., 2020. Fabrication of Copper Nano- Filter Membrane and its use in the Purification of Contaminated Water. Nigerian Journal of Environmental Sciences and Technology, 4(1), pp. 111-118. https://doi.org/10.36263/nijest.2020.01.0177 